\title{
TITLE:
}

\section{A New Species of Moolapheonoides (Crustacea : Amphipoda) from Sagami Bay, Japan}

AUTHOR(S):

Kobayashi, Takayuki; Ishimaru, Shin-ichi

\section{CITATION:}

Kobayashi, Takayuki ...[et al]. A New Species of Moolapheonoides (Crustacea:

Amphipoda) from Sagami Bay, Japan. PUBLICATIONS OF THE SETO MARINE BIOLOGICAL LABORATORY 2005, 40(3-4): 171-177

\section{ISSUE DATE:}

2005-12-25

URL:

http://hdl.handle.net/2433/176322

RIGHT: 
Publ. Seto Mar. Biol. Lab., 40 (3/4): 171-177, 2005

\title{
A New Species of Moolapheonoides (Crustacea: Amphipoda) from Sagami Bay, Japan
}

\author{
Takayuki KoBAYASHI) and Shin-ichi IsHIMARU ${ }^{2)}$ \\ ${ }^{1)}$ Wakamatu-nishi 1-17-20, Suzuka, Mie 510-0222, Japan \\ ${ }^{2}$ No-machi 3-19-60, Kanazawa, Ishikawa 921-8031, Japan
}

\begin{abstract}
A new species of the genus Moolapheonoides (Cyproideidae) is described from an intertidal gravel beach in Sagami Bay, central Japan. This is the first record of the genus from the Northern Hemisphere.
\end{abstract}

Key words: Gammaridea, Cyproideidae, Sagami Bay, the first record in the Northern Hemisphere

\section{Introduction}

The genus Moolapheonoides (type species: M. kadee Barnard, 1974) was established based on three species from Australia (Barnard, 1974). Though Moolapheonoides is similar to Austropheonoides and Narapheonoides in general morphology, the genus is easily distinguished from Austropheonoides by the presence of subchelate gnathopod 1, and from Narapheonoides by the presence of mandibular palp (Barnard, 1974; Barnard and Karaman, 1991). Moolapheonoides has been known to comprise only 5 species and 1 subspecies, all from the Southern Hemisphere (Barnard, 1974; Ledoyer, 1982; Myers, 1985; Thomas, 1999).

During the course of an ecological study of gammaridean amphipods conducted by the first author at Manazuru, west coast of Sagami Bay, many amphipod specimens were collected using sledge net. Among them, a small collection of an undescribed species of Moolapheonoides was found. This paper describes the new species, which is the first representative of Moolapheonoides in the Northern Hemisphere.

\section{Materials and Methods}

All specimens were collected by the first author, at Manazuru, Kanagawa Prefecture, Japan $\left(35^{\circ} 09^{\prime} \mathrm{N}, 139^{\circ} 09^{\prime} \mathrm{E}\right)$ on April 4, 1996. They were taken in very shallow water (about $0.9 \mathrm{~m}$ depth) with a sledge net $(0.1 \mathrm{~m}$ height, $0.3 \mathrm{~m}$ width, mesh size NGG54) by towing $9 \mathrm{~m}$ along the shoreline. Collection site was a sheltered gravel-beach. The samples from the net were immediately fixed with $5 \%$ buffered formalin-seawater, and they were sorted under a stereomicroscope and preserved in $70 \%$ ethanol in a laboratory.

The holotype and paratypes were dissected and mounted on glass slides with gum-chloral medium (Itô, 1985) dissolved with acid fuchsin.

The type-series are deposited in the National Science Museum, Tokyo (NSMT).

\section{Moolapheonoides acutifalcatus sp. nov.}

(Figs. 1-3)

Material examined

Holotype: NSMT-Cr 13417, ovigerous female (2.4 mm). Paratypes: NSMT-Cr 13418, juvenile no. 1 (1.9 mm); NSMT-Cr 13419, juvenile no. 2 (1.7mm); NSMT-Cr 13420, juvenile no. 3 (1.6 mm).

Etymology

The specific name, acutifalcatus, refers to the strongly curved dactylus of gnathopod 2 . 
Description of holotype (ovigerous female, $2.4 \mathrm{~mm}$ )

Head (Fig. 1A) rather small.

Antenna 1 (Fig. 1C) very short and stout, peduncular article 12.1 times as long as article 2, peduncular article 21.5 times as long as article 3; primary flagellum 1.7 times as long as article 3,4articulate, suddenly attenuating, article 1 with numerous aesthetasks; accessory flagellum buttonshaped. Antenna 2 (Fig. 1D) slender, 0.9 times as long as antenna 1, gland cone obtuse; flagellum 4articulate, 1.2 times as long as peduncular article 5 .

Mandible (Figs. 1G-I) with 3-articulate palp, article 2 as long as 1, article 3 twice as long as 2; molar process well-developed, triturating; incisor strongly dentate; lacinia mobilis on left mandible, strongly dentate; spine row with 8 spines on left and 9 spines on right.

Maxilla 1 (Fig. 1J): outer plate with 7 distal spines; inner plate small, with acute apex; palp 1articulate, with acute process apically, with 3 setae along lateral margin.

Maxilliped (Figs. 1L-N): inner plate with 2 apical spines and 2 mediofacial spines; outer plate with 2 apical spines, medial margin pubescent, lined with 3 or 4 setules; palp article 2 as long as article 1 , with 3 or 4 setae on mediodistal lobe; article 31.5 times as long as article 2 , distally produced, with apically 3 -forked stout spine and 1 seta on medial margin; article 4 as long as article 2 , falcate, apically blunt.

Gnathopod 1 (Figs. 2A, B) scarcely subchelate; coxa very small, hidden by coxa 3; basis slender, with short setules along anterior margin; carpus with distal lobe, reaching $1 / 3$ length of propodus, with 2 posterior setae marginally and 1 seta and 1 plumose spine apically; propodus 0.5 times as long as basis, 3.1 times as long as wide, with 2 plumose spines anteriorly; palm very short, palmar angle with 2 plumose spines; dactylus falcate, 3.3 times as long as palm, with tooth on distal $1 / 3$, accompanied with 8 small spines proximally. Gnathopod 2 (Figs. 2C, D) transverse or weakly parachelate; coxa very small, hidden by coxa 3 , with anterior seta; basis slender, with short setules along anterior margin; merus rounded distally, with tuft of spine-setae; carpus elongate, posterior margin with 1 seta, posterodistal lobe weak, accompanied with 2 setae and 1 plumose spine; propodus weakly dilating, as long as carpus, 2.4 times as long as wide; palm concave, palmar angle acute, with 2 spines; dactylus as long as palm, strongly curved, with distal tooth and 3 spines.

Pereopod 3 (Fig. 2E): coxa (Fig. 3A) very large, anterior margin rounded, posterior margin slightly concave; basis slender, with setules along anterior margin; merus with spines along both anterior and posterior margins; carpus and propodus of equal length, with spines along posterior margin; dactylus 0.5 times as long as propodus. Pereopod 4 (Fig. 2F): coxa (Fig. 3B) slightly larger than coxa 3 , anterior margin almost straight, posterior margin expanding posteriorly, slightly excavate; carpus to dactylus shorter than in pereopod 3. Pereopod 5 (Fig. $2 \mathrm{G}$ ): coxa expanding posteroventrally, about 1.7 times as broad as deep; basis linear, with 3 spines along anterior margin, with small spines along posterior margin; merus slightly longer than ischium, posterodistal angle weakly produced, with 3 small spines along posterior margin; carpus to dactylus missing. Pereopod 6 (Figs. 2H, I): coxa expanded posteroventrally; basis expanding posterodistally, ovato-rectangular, with 3 spines along anterior margin; posterodistal angle of merus subacutely produced, 0.4 times as long as anterior margin, with 3 small spines along posterior margin; carpus to dactylus missing. Pereopod 7 (Fig. 2J): basis, anterior margin shortened, with 5 spines, posterior lobe strongly expanding, widened distally, distal margin truncate, proximal angle acutely produced; posterodistal angle of merus subacutely produced, as long as anterior margin, with 2 small spines; carpus to dactylus missing.

Pleopods 1-3 (Figs. 3D-F) similar to each other; peduncle slightly shorter than rami, with 2 coupling spines on mediodistal angle; inner ramus consisting of 9 articles, outer ramus of 7 articles.

Uropod 1 (Fig. 3G) slender, longest, exceeding apex of uropod 3; peduncle minutely pectinate along medial margin; rami of subequal length, as long as peduncle, pectinate along medial margin. Uropod 2 (Fig. $3 \mathrm{H}$ ): peduncle minutely pectinate along medial margin; outer ramus as long as peduncle, 0.8 times as long as inner ramus. Uropod 3 (Fig. 3I): peduncle minutely pectinate along medial margin, sharpened on laterodistal end; inner ramus 1.8 times as long as peduncle; outer ramus 


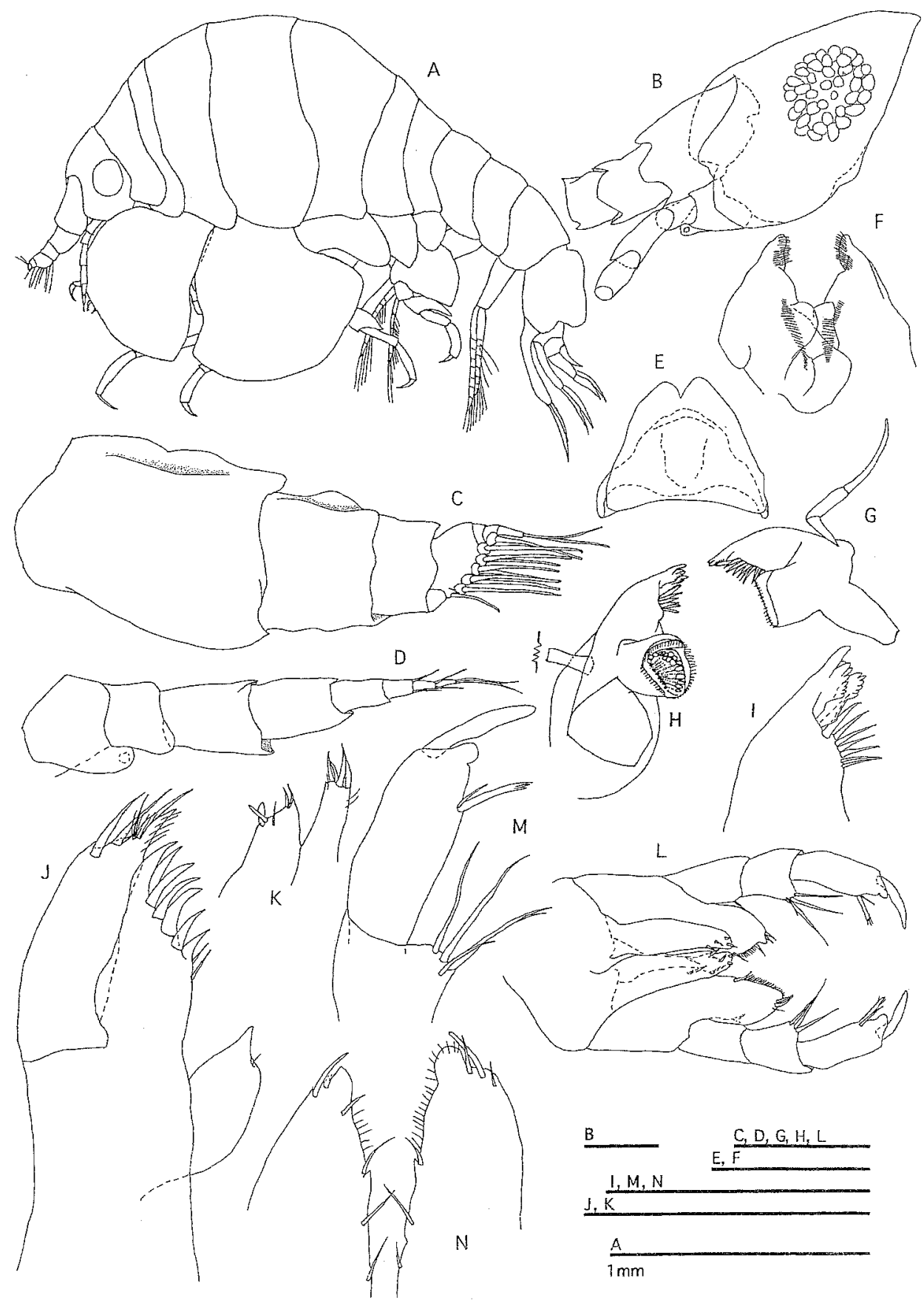

Fig. 1. Moolapheonoides acutifalcatus sp. nov. Holotype, ovigerous female (2.4 mm): A, habitus; C, antenna 1 (medial view); D, antenna 2 (medial view); G, right mandible; $\mathrm{H}$, left mandible; I, distal part of left mandible; J, maxilla 1; L, maxilliped; M, distal part of maxilliped palp; N, distal part of maxilliped outer plate. Paratype, no. 3, juvenile $(1.6 \mathrm{~mm}): \mathrm{B}$, head; $\mathrm{E}$, upper lip; $\mathrm{F}$, lower lip; $\mathrm{K}$, maxilla 2 . Scale bars $0.1 \mathrm{~mm}$, if not mentioned. 


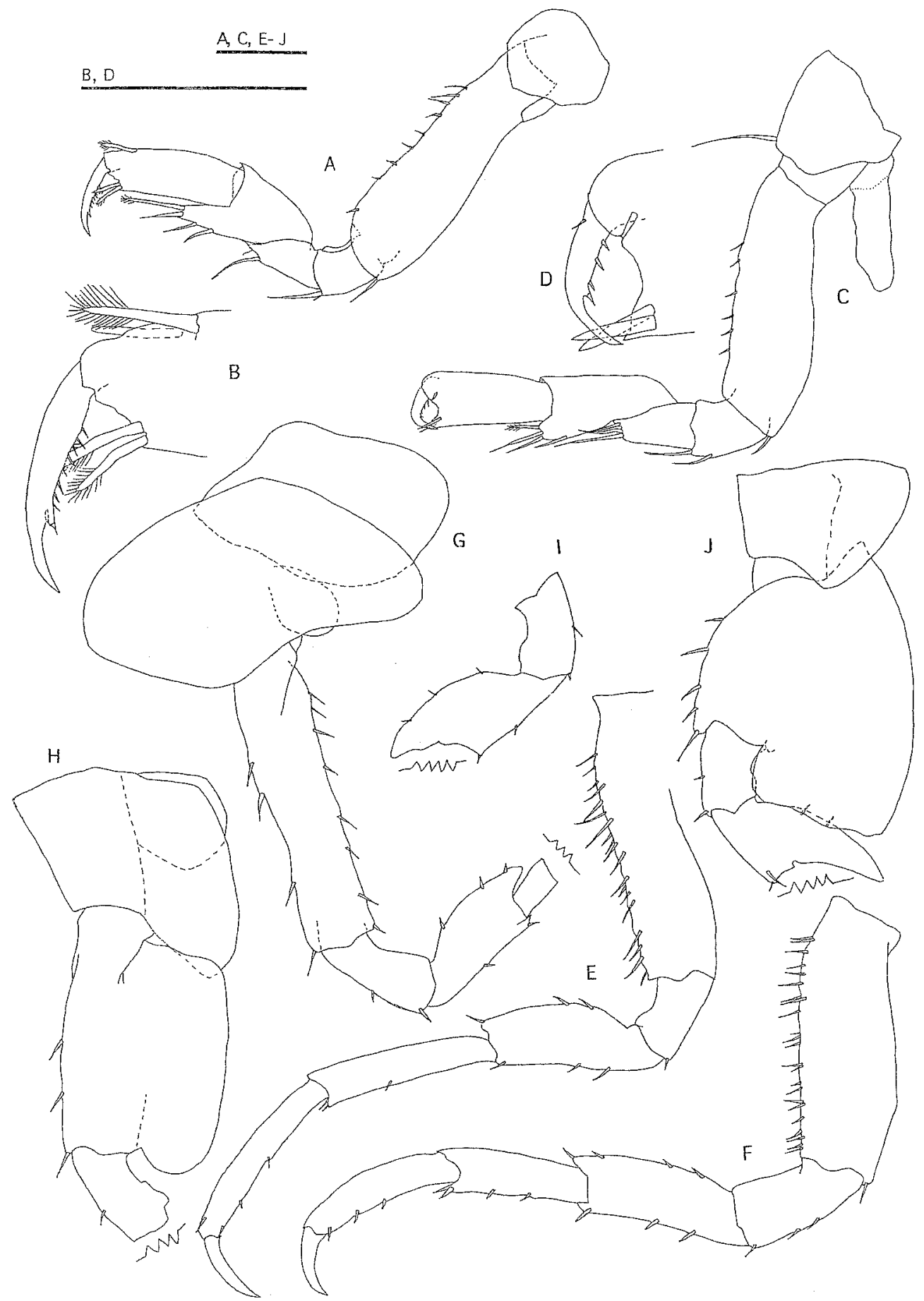

Fig. 2. Moolapheonoides acutifalcatus sp. nov. Holotype, ovigerous female (2.4 mm): A,B, gnathopod 1; C, D, gnathopod 2; E-H, pereopods 3-6; I, ischium and merus of right pereopod 6; J, pereopod 7. Scale bars $0.1 \mathrm{~mm}$. 


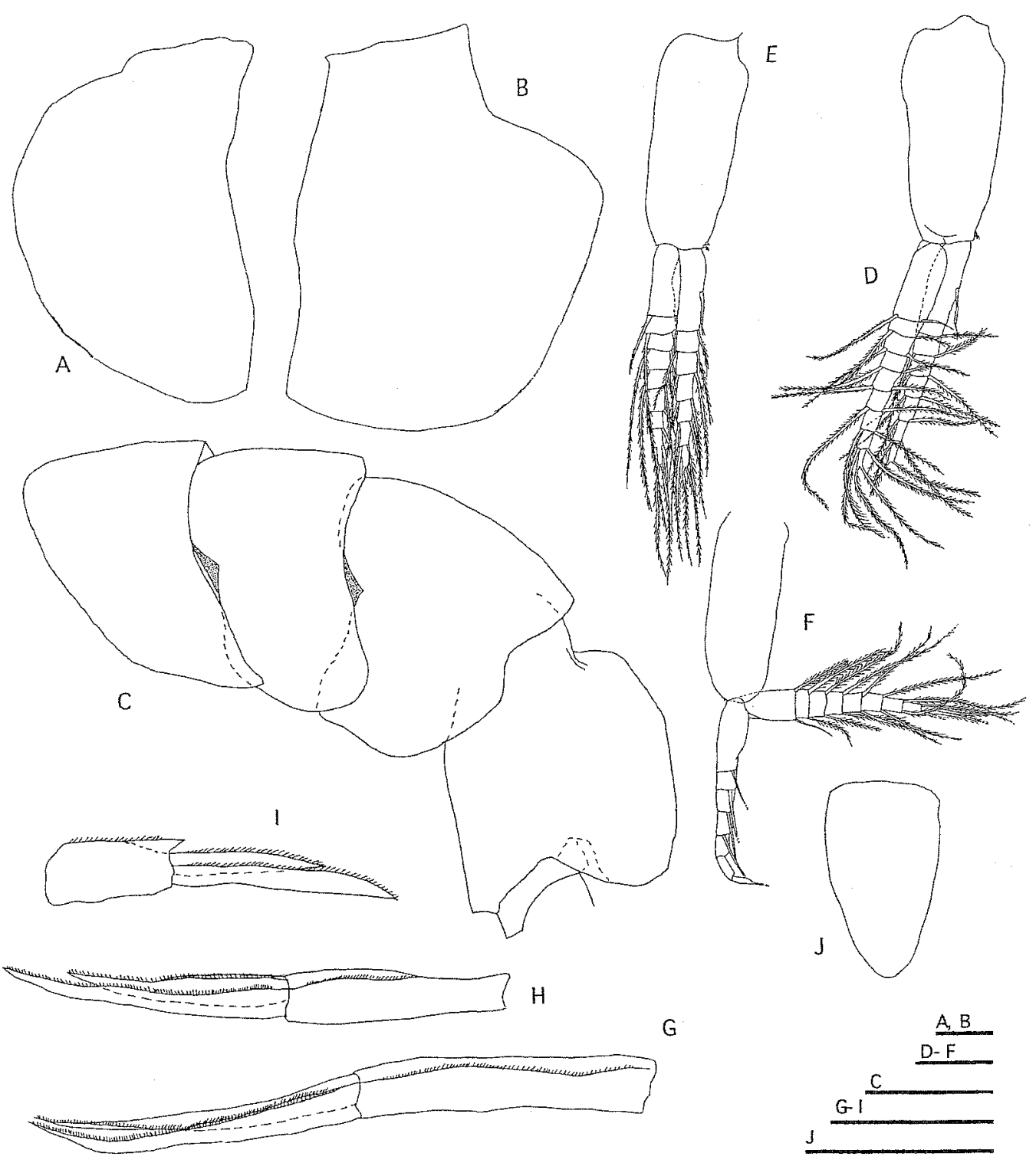

Fig. 3. Moolapheonoides acutifalcatus sp. nov. Holotype, ovigerous female (2.4 mm): A, coxa 3; B, coxa 4; D-F, pleopods 1-3; G, H, uropods 1, 2; I, right uropod 3. Paratype, no. 1, juvenile (1.9 $\mathrm{mm})$ : C, pleonites $1-3$ and urosomite 1. Paratype, no. 3, juvenile $(1.6 \mathrm{~mm})$ : J, Telson. 
0.7 times as long as inner ramus.

Description of paratype no. 1 (juvenile, $1.9 \mathrm{~mm}$ )

Epimeral plate 1 (Fig. 3C): posteroventral angle acutely produced. Epimeral plate 2 (Fig. 3C) posteroventrally rounded. Epimeral plate 3 (Fig. 3C) with concave ventral margin, posteroventral angle obtusely beveled.

Urosomite 1 (Fig. 3C) very large, dorsally keeled; dorsal keel low, evenly truncate, its height 0.3 times as long as its length.

Description of paratype no. 3 (juvenile, $1.6 \mathrm{~mm}$ )

Head (Fig. 1B): rostrum of medium length, with blunt apex; lateral cephalic lobe broad, weakly emarginate. Eyes large, round.

Upper lip (Fig. 1E) apically bilobate, symmetrical. Lower lip (Fig. 1F): shoulders bluntly produced inward.

Maxilla 2 (Fig. 1K): outer plate narrow, with 4 spines and 1 seta distally; inner plate with 2 small spines on laterodistal corner, 2 large spines and 1 seta on mediodistal corner.

Telson (Fig. 3J) entire, 1.8 times as long as wide, semioval.

Remarks

This species exhibits morphological characters provided below, which were designated as diagnoses of the genus Moolapheonoides (Barnard, 1974; Thomas, 1999); mandible has 3-articulate palp; gnathopod 1 is scarcely subchelate and its propodus is neither attenuate nor tapering; coxae 3-4 are immensely broadened, with contiguous margins abutting; coxa 2 is hidden; bases of pereopod 6-7 are expanded; urosomite 1 is dorsally keeled, elongate.; telson is elongate, almost reaching apex of peduncle on uropod 3.

The genus Moolapheonoides has been reported only from the Southern Hemisphere: M. kadee Barnard, 1974, M. coocoo Barnard, 1974 and M. poontee Barnard, 1974 from Australia, M. angustipes Ledoyer, 1982 from Madagascar, M. coocoo serua Myers, 1985 from Fiji, and M. utmas Thomas, 1999 from Papua New Guinea. The present new species is the first representative of the genus from the Northern Hemisphere, extending the distribution of Moolapheonoides to the North Pacific.

Apparently this species is very rare at this sampling station, as the specimens were caught only in several tows on a day (see Materials and Methods) throughout the monthly samplings which were carried out every $1 \mathrm{~h}$ for $24 \mathrm{~h}$ from November 1995 to October 1996.

The new species is distinguished from $M$. kadee in the following points: accessory flagellum is shorter; medial margin of outer plate on maxilliped is pubescent, lined with 3 or 4 setules; propodus of gnathopod 1 lacks spines on posterior margin; dactylus of gnathopod 2 is strongly curved and armed with several spines; bases of pereopods 3-5 are lined with setules more densely; basis of pereopod 7 is trapezoidal; dorsal keel of urosomite 1 is low and evenly truncate.

Differing from $M$. coocoo, lateral cephalic lobe is broad; article 3 of mandibular palp is elongate; propodus of gnathopod 1 lacks posterior spines; palm of gnathopod 2 is evenly excavate; ischia of pereopods 5-7 are not elongate; basis of pereopod 7 is trapezoidal; dorsal tooth is lacking on pleonite 3 ; and dorsal keel on urosomite 1 is not recurved anteriorly.

From M. poontee, lateral cephalic lobe is broad; accessory flagellum is short; outer lobe of lower lip is notched; coxa 1 is not produced anteriorly; basis of gnathopod 1 is less setulose; posterior margin of propodus of gnathopod 1 is naked; posterodistal lobe of article 5 of gnathopod 2 is less elongate; palm of gnathopod 2 is not oblique; posterior lobe of coxa 6 is deeper; basis of pereopod 7 is more expanding and trapezoidal; dorsal tooth is lacking on pleonite 3; dorsal keel on urosomite 1 is taller in posterior extension.

From $M$. angustipes, lateral cephalic lobe is broad, almost truncato-concave; bases of gnathopods and pereopods are armed with several setules or small spines; basis of pereopod 6 is ovate; basis of 
pereopod 7 is trapezoidal; and dorsal keel of urosomite 1 is not acute posteriorly.

From $M$. coocoo serua, lateral cephalic lobe is broad; palm of gnathopod 2 is evenly excavate; bases of pereopods 3 and 4 are armed with several setules; and ischia of pereopods 5-7 are not elongate.

From $M$. utmas, basis of gnathopod 1 is armed with several setules or small spines; posterodistal lobe of article 5 of gnathopod 2 is less elongate; propodus of gnathopod 2 is not armed with posterior spine; palm of gnathopod 2 is not oblique; ischia of pereopods 5-7 are not elongate; basis of pereopod 7 is truncate along distal margin.

A simple key of the genus Moolapheonoides:

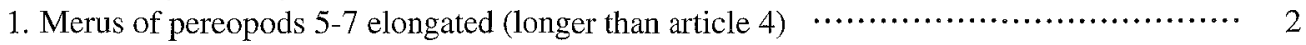

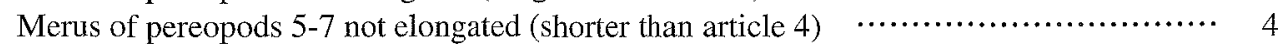

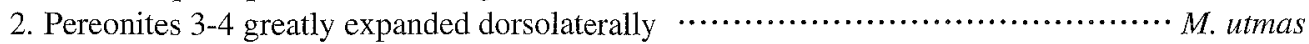

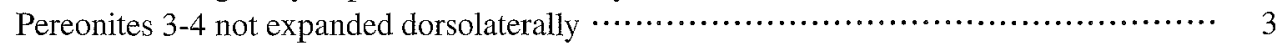

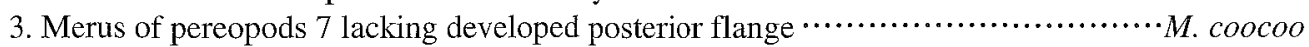

Merus of pereopods 7 with developed posterior flange, broadest distally $\cdots \cdots \cdot$. coocoo serua

4. Gnathopod 2 with posterior seta on palm (besides defining setae of palm)

M. poontee

Gnathopod 2 lacking posterior setae on palm (besides defining setae of palm) …......... 5

5. Basis of pereopod 6 slender and not lobate, gnathopod 2 lacking posterior seta on palm

Basis of percopod 6 broad and lobate, gnathopod 2 with posterior seta on patm

6. Dactylus of gnathopod 2 strongly curved and with several spines on posterior margin

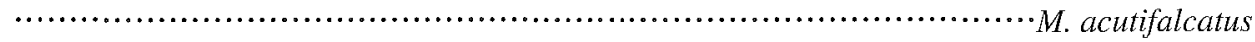

Dactylus of gnathopod 2 not strongly curved and lacking several spines on posterior margin

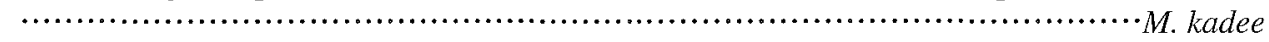

\section{Acknowledgments}

We wish to express our sincere gratitude to Dr. Shigeyuki Yamato (Seto Marine Biological Laboratory, Kyoto University) for his critical reading of the manuscript.

\section{References}

Barnard, J. L. 1972. Gammaridean Amphipoda of Australia, Part I. Smithsonian Contributions to Zoology, 103, 1333.

Barnard, J. L. 1974. Gammaridean Amphipoda of Australia, Part II. Smithsonian Contributions to Zoology, 139, 1148.

Barnard, J. L. and G. S. Karaman 1991. The families and genera of marine gammaridean Amphipoda (except marine gammaroids). Records of Australian Museum, Supplement 13 (Part 1 and 2), 1-866.

Itô, T. 1985. Organisms in sand interstices. Kaimeisha, Tokyo, 241 pp. (in Japanese)

Ledoyer, M. 1982. Crustacés amphipodes gammariens familles des Acanthonotozomatidae à Gammaridae. Faune de Madagascar, 59 (1), 1-598.

Myers, A. A. 1985. Shallow-water, coral reef and mangrove Amphipoda (Gammaridea) of Fiji. Records of Australian Museum, Supplement 5, 1-144.

Thomas, J. D. 1999. Moolapheonoides utmas, new species, from coral reefs in the Madang lagoon, Papua New Guinea (Amphipoda, Cyproideidae). Bulletin of Marine Science, 65 (2), 515-521. 